\title{
A multidimensionalidade do conceito da violência: elementos para o debate
}

\author{
Arlindo da Silva Lourenço* \\ Renata Marcílio Cândido**
}

\section{Resumo}

A multiplicidade de tratamento das questões sociais emergentes atuais é infinita; diversas possibilidades de análise de encaminhamentos teóricos são possíveis para variadas questões, a partir de distintos estudiosos. Considerando tais possibilidades, pretende-se, neste ensaio, problematizar o conceito de violência, utilizando para isso teóricos das áreas da psicologia, da psicanálise, da sociologia e da educação. Mais do que propor alternativas para a superação do fenômeno violência, almeja-se evidenciá-lo em sua perspectiva complexa e multifacetada, indicando o processo educacional no seu compromisso de humanização como possibilidade de emancipação da razão e de superação das ações humanas consideradas violentas neste mundo já tão fragmentado, cujas relações sociais encontram-se tão reificadas.

Palavras-chave: Violência. Violência na escola. Reflexão. Civilização e educação.

*Doutor em Psicologia pela USP-SP. Professor do Departamento de Saúde III da UNINOVE-SP e pesquisador do Laboratório de Estudos sobre o Preconceito da USP (LaEP-USP).

**Doutora em Educação pela Faculdade de Educação da USP-SP. Professora do Departamento de Pedagogia da UNIFESPGuarulhos.

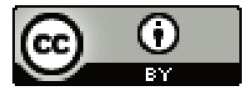




\section{Introdução}

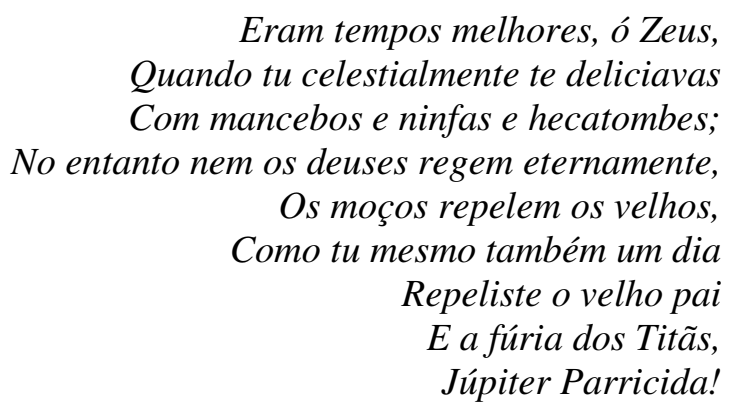

(HEINE, 2011, p. 16)

Este artigo pretende analisar o conceito de violência a partir de teóricos críticos oriundos da psicologia, da psicanálise, da sociologia e da educação em suas múltiplas facetas e características, problematizando questões há muito pertinentes para aqueles que pensam o mundo em suas relações multidimensionais: sociais, econômicas, políticas e educacionais, assim como algumas possibilidades, ainda que teóricas num primeiro momento, de superação deste fenômeno por meio de uma escola e de uma escolarização que levem em consideração a emancipação humana como objetivo da mais alta estima. Trazemos a realidade de uma escola em que a violência é produto das próprias relações interpessoais fortemente hierarquizadas, onde o estabelecimento do currículo e do que os estudantes devem aprender é dado de forma naturalizada, sem levar em conta as reais necessidades dos indivíduos presentes na escola, tampouco da própria sociedade em que esta se insere. Uma escola muito diferente da que se deseja, ou seja, que trabalhe pela autonomia dos sujeitos; nela, a violência escolar faz ponte incessante com a violência extramuros de forma dialética: “[...] qualquer debate acerca de metas educacionais carece de significado e importância frente a essa meta: que Auschwitz não se repita. Ela foi a barbárie contra a qual se dirige toda a educação" (ADORNO, 2000, p. 119).

Para se compreender a violência na multidimensionalidade de suas marcas, mais visíveis ou mesmo invisíveis, é necessário que se entenda a própria dimensionalidade existencial, singular e múltipla, da vida humana e das realidades sociais, históricas e culturais estabelecidas ao longo da jornada desses Homo-sapiens neste planeta. Aqui se encontra uma grande dificuldade para os humanos, especialmente aqueles mais vulnerabilizados social e financeiramente: uma anacrônica e ao mesmo tempo moderna incapacidade de convivência pacífica com o "outro", com o "diferente", bem como com aquelesa que se assemelha na singularidade do corpo, mas dos quais se distancia em relação aos 
traços de familiaridade. E não só estes, para quem o mundo e a realidade a sua volta, repletos de lógicas perversas que não permitem que suas vidas sejam vividas na plenitude, não deixam escapar o significado de existência em condições extremadas, mas também, como já dizia Albert Camus, em “O Verão - Regresso à Tipasa" (1954), que no mundo "há a beleza e há os humilhados": de algum lugar desses dois pólos, encontramo-nos todos.

Estabelecem-se como marco de discussão inicial do fenômeno da violência os três grandes teóricos da sociedade e da vida humana que, de certa forma, revolucionaram nossa forma de pensar, sentir e agir: Darwin, Marx e Freud, mas, principalmente, este último. Parte-se, na sequência do texto, para aqueles teóricos que pensaram criticamente a escola, bem como os caminhos possíveis para que ela se transforme, efetivamente, em um pilar de construção de uma sociedade mais livre e justa, em um lugar onde a violência, apesar de seu caráter instintivo, muito marcante e presente desde tempos imemoriais na humanidade, seja um evento de exceção, e não a regra social par excellence.

\section{Desbravando as fronteiras da violência primeva}

Charles Darwin, Karl Marx e Sigmund Freud, para citar os desbravadores das fronteiras das ciências naturais e humanas, já denunciavam, cada um em seu tempo, a pesada carga de infelicidade e injustiça que pairava sobre os destinos da humanidade: fosse entendida como lei natural que estabeleceria o primado da força e da resistência, movendo as espécies para patamares mais elevados de vida em constante evolução, onde os mais fortes ou mais bem adaptados prevaleceriam em detrimento dos mais fracos e vulnerabilizados; fosse também em razão de uma suposta contenda primitiva envolvendo o chefe da horda, que, negando veementemente a seus filhos machos a primazia ou o "direito" de livre acesso às fêmeas, expulsava-os deliberadamente do clã, tão logo suas ações representassem quaisquer perigos à manutenção do status original:

Suas pesquisas (de Charles Darwin) declaram, explicitamente, que o confronto e a violência entre espécies distintas, e mesmo no interior de cada uma delas, é umbilical na história de todos os animais pertencentes à escala zoológica, incluindo-se o homo sapiens. Mais do que isso, essa "competição pela vida" e essa "seleção natural", ambas foram necessárias para os progressos verificados nos organismos vivos, desde sua mais remota origem, e funcionaram como um processo de depuração morfológica e sistêmica. (MURAD, 2007, grifos nossos). 
Já para Karl Marx (1996, p. 370), embora reconhecesse certa "potência” na violência, principalmente quando identificava nesta "a parteira de toda velha sociedade que está prenhe de uma nova. Ela mesma é uma potência econômica", o desenvolvimento das forças produtivas responsáveis por mover o progresso dessa mesma humanidade, a submissão, a exploração e o domínio de alguns (os "falsos donos da força de trabalho") por outros (os "senhores legítimos” dos meios de produção), levariam a uma acirrada e sangrenta disputa entre classes de pessoas e/ou raças, que já se mostrou na história de forma cruel e destruidora.

[...] a forma capitalista da grande indústria reproduz ainda mais monstruosamente aquela divisão do trabalho, na fábrica propriamente dita, por meio da transformação do trabalhador em acessório consciente de uma máquina parcelar e, em todos os outros lugares, em parte mediante o uso esporádico das máquinas e do trabalho das máquinas, em parte por meio da introdução de trabalho feminino, infantil e não qualificado como nova base da divisão do trabalho. A contradição entre a divisão manufatureira do trabalho e a essência da grande indústria impõe-se com violência. (MARX, 1996, p. 112-113, grifos nossos).

Finalmente, para Sigmund Freud, o processo civilizatório da humanidade pressupõe um quantum de repressão dos impulsos e dos desejos, acarretando lutas (internas e externas) da vida contra a morte, em que a violência está presente desde tempos imemoriais e, parece, é condição inerente ao homem; necessária num certo sentido e num determinado limiar para o progresso, mas merecedora de nossas mais altas possibilidades de repressão, se quisermos continuar a habitar este planeta por tempo maior do que o que até agora conseguimos a duras penas. Força e resistência dos organismos que mais se adaptam às condições eventualmente inóspitas dadas pela natureza; trabalho humano como fator desencadeante de mais-valia e, consequentemente, mais repressão e liberação das forças impulsivas (auto) destruidoras após um período de recalque e submissão física e psicológica estariam, assim, na origem do fenômeno da violência.

Em “Totem e Tabu”, de 1913, Freud traça um início hipotético para a corrente civilizatória da humanidade baseando-se, justamente, nas teorias evolucionistas, representadas, principalmente, por Darwin. Logo depois de o ser humano estabelecer uma postura ereta e olhar de forma horizontal o mundo ao redor, um crime bastante cruel precisou ser cometido: investindo contra a tirania de um pai/dono/patrão castrador e inibidor, uma reunião de pessoas (os irmãos da tribo em constante submissão) precisou ser feita. E traçou não apenas a destituição daquele poder soberano e totalitário que atentava contra toda a população da horda primitiva mas também o assassinato primevo e a liberalização de novas forças progressivas. Como esse assassinato também gerou, ao lado da alegria 
pelo fim da dominação doravante estabelecida, certos sentimentos de culpa pela perda da proteção infantilizada, o corpo do pai precisou ser assimilado, ingerido e internalizado, como foram introjetados também os aspectos internos tão temidos daquela figura representativa da autoridade. Para que a incorporação desses aspectos paternos (a propriedade das mulheres, a proteção da tribo e sua manutenção sob algum controle) não se retroalimentasse nos descendentes, em uma nova onda de arbitrariedades e leviandades, foi necessário combinar entre os remanescentes novas regras e novos padrões de existência que possibilitassem a sua coexistência "pacífica" na nova comunidade. Nasceram aqui a família, as noções de pai/mãe e filhos, a lei e a ordem, tratadas de "comum acordo".

Essa ordem pretensamente estabelecida de maneira fraternal se constituía apenas precariamente, já que não era incomum que a resposta aos pactos realizados não fosse devidamente cumprida ou satisfeita. Um cenário de amor e ódio compõe, para Freud, portanto, o início da civilização. Este cenário fará parte da trajetória do homem no planeta, com momentos acentuados de trégua, intercalados a outros momentos generalizados de barbárie, como o foi em quase todo o período da idade média, com a "Santa Inquisição"; como foi, depois, com o advento de revoluções por direitos e de duas grandes guerras mundiais, que exterminaram povos, nações e países inteiros; e como é hoje, com o extermínio de jovens negros e moradores das periferias brasileiras pelas forças policiais estaduais e a onda racista, eugenista e xenofóbica europeia contra os povos do oriente médio que fogem justamente de guerras e conflitos armados internos existentes em suas pátrias, na busca de novos e melhores lares para si e para suas famílias.

Em uma resposta a Albert Einstein, que lhe perguntava "Porque a Guerra?", o criador da psicanálise reafirma o caráter paradoxal do crime que permite ao homem civilizar-se. Em "Reflexões para os tempos de guerra e morte", de 1932, Freud tenta responder ao físico alemão se a humanidade, constituída daquela forma original, primordial, caminhava para a destruição. Suas considerações versam sobre a legitimidade do recalque e da repressão das pulsões, assim como sobre a "racionalidade da guerra entre civilizados", diferenciando-a da guerra entre povos considerados primitivos e entre esses povos e os povos tidos como civilizados. Clara e enfatizada deve estar a discordância tácita destes dois cientistas humanistas e pacifistas em relação a todos esses conflitos armados. Entretanto certo impulso para a "inatividade original", ou para o estado de inércia e repouso do qual fomos gerados, já era um dos temas de pesquisa do autor da psicanálise, a consequente batalha entre Eros e Thânatos (Vida e Morte, Amor e Ódio), como uma batalha interior considerada longe do fim. 
Apesar do estabelecimento de leis e das instituições que devem regular a vida entre os homens no mundo, uma parcela significativa de transgressão era previsível para Freud, já que não é possível passar completamente incólume à repressão dos impulsos ou à plena domesticação deles sem uma dose de infelicidade e ressentimento. Por outro lado, questiona-se: qual a legitimidade do Estado, enquanto instituidor da lei e da ordem, para cobrar obediência de seus súditos, quando ele mesmo, em sua constituição, dá livre curso a seus desejos e impulsos, como é o caso da fabricação das guerras e da exploração de pessoas, com impostos abusivos e aleatórios? É possível o assentamento humano demarcado nas bases determinadas? Ora, os impulsos não são bons nem maus; entretanto a generalizada castração destes impulsos leva a um estado de desequilíbrio que pode ser mortal (pensemos nas duras realidades vividas pelos alemães nos anos iniciais do século, especialmente os historicamente mais vulnerabilizados, como os trabalhadores, com a perda de parte de seu território, com o desemprego em massa, com a hiperdesvalorização de sua moeda e com a humilhação imposta pelos outros países após a sua derrota na primeira guerra mundial, impondo-lhes o Tratado de Versalhes em 1919. Daqui para o aparecimento de um "messias libertador", como se autodenominou Adolf Hitler, por exemplo, é apenas um pequeno passo!).

A isto tudo deve ser acrescentado o fato de que, ao lado das instituições originariamente criadas (a comunidade, o grupo e a família), a sociedade foi estabelecendo outras (as instituições econômicas, as políticas e as religiosas). Com o aparecimento destas, segundo Marcuse (1972), o homem ganhou "mais-repressão", ou aquele quinhão a mais de repressão que visa manter a dominação sob o princípio do desempenho individual e coletivo. Desejando a morte e a destruição do outro, nosso inconsciente foge completamente daquele pedaço de racionalidade ainda existente no superego e, quando dissolvido na massa, por um processo parecido com a hipnose e o sonambulismo, torna-se mortífero, segundo Gustave Le Bon (2008). Quando aparece fora de lugar, a consequência inevitável é a destruição generalizada; esta é uma resposta significativa para o avanço do nacional-socialismo em meados da quase-metade do século passado e para a submissão completa da quase-totalidade de um povo considerado culto a um líder fanático, autoritário, supersticioso e lunático.

A linguagem da violência, inscrita nos recônditos de todos nós, é a da "Lei e da Ordem" e, portanto, do recalque; ou seja, daquilo que não nos é permitido exprimir em determinadas situações e condições sociais. O que permanece destas linhas é que, apesar do esforço da razão, instrumentalizada que foi ao longo do tempo do processo civilizatório, o que predomina ainda são as forças instintivas reprimidas: continuamos sozinhos, apesar da incessante busca de apoio e auxílio no outro. Segundo 
Camus (1965, p. 854 apud MATTEÍ, 2002, p. 331): “conquistamos por nossa vez, deslocamos limites, dominamos céu e terra. Nossa razão produziu o vazio. Enfim sós, concluímos nosso império sobre um deserto".

Um dos estados exigidos pela violência é a obediência; o vazio existencial muitas vezes sentido por nós faz com que obedeçamos incondicionalmente a ordens e leis vulgarmente absurdas; é o caso, por exemplo, de muitos líderes e chefes do nacional-socialismo alemão da década de 1940. Talvez uma das figuras mais caricaturais daquela expressão de passividade frente ao absurdo seja a de Adolf Eichmann, responsável por toda operacionalização logística de transporte de prisioneiros nazistas aos campos de tortura, sofrimento e morte à época do nazismo do Terceiro Reich. Questionado sobre os motivos que o teriam levado a cumprir ordens que condenavam milhares de pessoas à morte nos campos de concentração à época da segunda guerra mundial, disse, simplesmente, que cumpria ordens de seus superiores. Para Arendt (2010), este senhor era: "um arrivista de pouca inteligência, uma nulidade pronta a obedecer a qualquer voz imperativa, um funcionário incapaz de discriminação moral". Da incapacidade de compreender o estrangeiro (o bárbaro) para a incapacidade de compreender o diferente (o outro), foi um pequeno pulo na história da humanidade: "quando a civilização oscila entre a paranoia e a perversão, a barbárie não está longe” (ENRIQUEZ, 1991, p. 371).

\section{A banalização da violência}

Se a violência está presente na história humana como fenômeno implícito da própria existência, a banalização do mal e, ainda, a banalização da violência parecem ser um fenômeno a que, no fundo, nos acostumamos; alguns homens, grupos ou povos, inclusive, parecem que se esforçam em mantê-la à vista, como é o caso do conflito, que resiste ao tempo, entre judeus e palestinos, no oriente médio, ou do próprio antissemitismo, fenômeno que remonta, segundo historiadores, ao ano de 70 d.C, quando ocorreu a “destruição do segundo Templo e da diáspora em massa” (BAUMAN, 1998b, p. 54).

A violência é tornada corriqueira, comezinha, banal e vizinha; assim, negligenciada e naturalizada, jamais é vista como um mal que pode aniquilar a possibilidade do amanhã: em nossas televisões de todos os dias, no noticiário, em horário nobre, por exemplo, uma notícia trágica, de morte, guerra, crime ou violência, sempre sucede a outra, mais suave, ligada à estética, ao estilo de vida 
burguês, do mundo esportivo ou artístico, constituindo-se em outro tipo de violência, a "simbólica", segundo Bourdieu (1978). É simbólica porque imposta de forma legítima e dissimulada pelos detentores do capital político e cultural de um povo, portanto difere, como representação, daquela violência clássica a que estamos acostumados; é o espetáculo da redundância, da massificação e da reificação, no qual cada um de nós torna-se mero objeto para outro. E, na condição de objeto, invisível (observemos as filas nos pontos de parada de ônibus, as filas nos bancos ou supermercados e podemos contar a pequena porcentagem de pessoas que conseguem notar o outro ao seu redor).

A diferença entre pessoas semelhantes na "sociedade de consumidores" (BAUMANN, 1998a) é tornada desigualdade; daí para o racismo, o preconceito e a discriminação do outro é um passo muito curto. Somos seres pós-modernos, globalizados e tecnologicamente interligados vivendo em uma “sociedade unidimensional” (MARCUSE, 1973). O progresso técnico e tecnológico, que deveria levar o homem aos patamares de bem-estar e vida comum imaginados pelos iluministas do século XVIII, é, na verdade, um engodo, uma farsa e um desastre: “apesar de todos os nossos progressos, nós somos, ainda e sempre, bárbaros" (MATTEÍ, 2002, p. 19). Não devemos, apesar disso, ser contrários ao progresso ou mesmo à tecnologia, mas sim a tudo de perverso que esse progresso e essa tecnologia tragam consigo. Isto só é possível por meio da razão, que "não existe por natureza, mas realmente apenas por decisão. Não acontece por si mesma, como um fato natural e como a totalidade da existência humana concreta, na medida em que esta tem caráter de natureza, mas nasce da liberdade" (JASPERS, 1958, p. 57).

As sociedades democráticas modernas ao redor do planeta, em maior ou menor grau, só conseguiram assegurar em partes a satisfação de uma vida de necessidades requeridas pelos cidadãos; algumas delas nem aquelas mais básicas, como alimentação, vestuário ou abrigo. Sob o comando e controle de uma classe dominante muitas vezes tornada perversa, o desenvolvimento interior do homem é limitado e impedido de se realizar às vezes já durante algumas concepções nascidas de relações violentadas. O futuro é repleto de incertezas, os sujeitos se tornam descartáveis e meras engrenagens da máquina social e, portanto, redundantes e plenamente rejeitáveis como peças que se apodrecem ou deterioram. E, ao chegar neste nível, são trocadas por outras em melhor estado; ao se constituir como força-de-trabalho, morre vivendo uma vida miserável: "só existem loucos perigosos no poder", já dizia Michel Serres em entrevista concedida em 1972, intitulada “Tanatocracia” (SERRES 2005). 
Para Hannah Arendt, se o poder pode ser legítimo, a violência nunca o é, exigindo sempre uma justificação (ARENDT, 2010a). O estado democrático, por depender do voto do eleitor contribuinte, cioso dos seus deveres como cidadão empenhado na Pólis, está amarrado e amordaçado, porque submisso ao poderio das grandes companhias corporativas e das famílias bilionárias abastadas, que detêm, juntas, quase $4 / 5$ de toda a riqueza produzida pelos homens e mulheres no planeta ${ }^{1}$. A política, que deveria ser o espaço de expressão das opiniões de um povo, esboça-se inquebrantável, sem fissuras ou rachaduras que permitiriam a distribuição mais equitativa do poder. Essa história da autonomia dos homens nos conduziu à tirania das possibilidades, segundo Arendt, já mencionada. Onde ficam "a beleza sem solidariedade" (CAMUS, 1954) ou a liberdade sem comida e abrigo para todos (HELLER, 1982)? Será a falta de amor e de afeto nos primeiros anos, o desaparecimento do "seio bom" (KLEIN, 1969), a causa de tanta tragédia humana? "O outro guarda um segredo; o segredo do que eu sou" (SARTRE apud LEITE, 2008, p. 280). Mais do que palavras de ordens ou clichês, é necessário encontrar, no outro, o espelho com a imagem de quem sou: "os desejos, sonhos, impulsos e emoções que investigamos fora, se movem silenciosamente em nós e são parte de nossas ações" (DAMERGIAN, 1991, p. 65).

Um mundo que se queira justo precisa querer sempre mais dessa justiça; aceitar o risco é dar sentido à vida, segundo o ideal de existência do mundo grego clássico. Um novo humanismo pressupõe "relações humanas compatíveis com a preconizada ideologia de valorização da diversidade dos grupos, instaurando uma cultura da paz e formando um modelo planetário de homem" (BALDUCCI, 1990 apud TASSARA; DAMERGIAN, 1996, p. 301). Para suplantar-se o "Horror Econômico" (FORRESTER, 1997) ou a "Economia Bandida" (NAPOLEONI, 2010), são necessários coragem, egos e superegos fortalecidos pela solidariedade, que são possíveis naqueles grupos dos quais se participa, onde a integridade e o caráter genuíno dos sujeitos são respeitados; essa coragem deve representar o nosso "segundo nascimento" (ARENDT, 2005), aquele momento de nossa ação no mundo dos homens, do nosso discurso, da nossa militância e de nossa práxis como habitantes da pólis.

Arendt (2005) não tinha dúvidas de que essa prática política representava verdadeiramente a revolução, e não a reforma, como nos acostumamos a fazer e a aceitar que façam. Enquanto a natalidade é algo novo e, portanto, nova possibilidade, o discurso entre iguais representa essa segunda natalidade ou o momento em que deixamos o comezinho chão de nossas vidas privadas e (re) fundamos o espaço público do debate e da ação. Contra os riscos de um "pensamento único" (TOURAINE, 
1996), um pensamento que leve em conta o outro no mundo; contra a ideologia de uma sociedade unidimensional (MARCUSE, 1973), uma sociedade fundada na pluralidade e na busca por justiça e verdade. Por enquanto, contudo, ainda estamos navegando por mares desconhecidos e "todo continua siendo possible, pero todo continúa incierto" (WALLERSTEIN, 1994, p. 154).

Já sabemos, de certa maneira, dos erros históricos do passado; inferindo sobre os perigos do futuro, na suposição de se manterem as coisas como se encontram na contemporaneidade nossa de cada dia, o rompimento com a ideologia dominante não é apenas necessário mas também uma tarefa das mais urgentes. Esse "último refúgio" precisa fugir à lógica da destruição massiva das instituições sociais pelo estado sádico e sedento, perverso portanto. Da forma como está, é facilmente capturado nas malhas nem sempre visíveis da lógica capitalista selvagem: “outro mundo é possível”, já que "este mundo de merda está grávido de outro" (GALEANO, 2011) ${ }^{2}$, justamente aquele mundo cuja potência compreenderia a maioria, se não a totalidade das pessoas, e não a minoria, como agora vemos.

\section{A escola e a violência}

Nesse caminho cheio de dúvidas, incertezas, desvios e atalhos, a escola é fundamental e reafirmamos que: "[...] qualquer debate acerca de metas educacionais carece de significado e importância frente a essa meta: que Auschwitz não se repita” (ADORNO, 2000, p. 119). Para além da pseudoformação, que arrasa o pensamento e a possibilidade de se refletir sobre a própria miséria da existência, deve-se prever e buscar a emancipação do sujeito.

Para Matteí (2002), é necessário resgatar o caráter sagrado da skolé, como lugar do otium criativo e como lócus por excelência da possibilidade estética do homem. Esta, a escola, deve-se colocar "de fora", em outro espaço, que não aquele destinado às instituições como um todo, já que, se assim for, será "mais uma delas” e, como tal, passível da mesma violência cotidiana, como atestam os inúmeros casos relatados em seu interior; de alunos contra alunos; alunos contra professores; professores contra professores; comunidade contra escola, todos acontecidos nos últimos anos, em vários cantos do planeta.

Caberia distinguir, assim como propõe Charlot (2002), ao menos duas categorias de análise da violência no contexto escolar: a primeira, aquela que se reproduz intramuros, sem estar relacionada às 
atividades por excelência da instituição de ensino; neste caso, apesar de a violência ter sido cometida no ambiente escolar, por exemplo, "quando um bando entra na escola para acertar contas das disputas que são as do bairro ou comunidade, a escola é apenas o lugar de uma violência que teria podido acontecer em qualquer outro lugar" (CHARLOT, 2002, p. 434). Ou seja, a escola é apenas mais um dentre tantos outros locais possíveis para a ocorrência da violência, o que não se relaciona, fundamentalmente, à instituição em si, que neste caso figura tão somente como o espaço onde a ação violenta foi possível. A segunda categoria analítica referida pelo autor seria aquela em que há violência relacionada à natureza e às atividades da instituição escolar, a violência à escola — por exemplo, "quando os alunos provocam incêndios, batem nos professores ou os insultam, eles se entregam a violências que visam diretamente à instituição e àqueles que a representam” (CHARLOT, 2002, p.434). Neste caso:

Essa violência contra a escola deve ser analisada junto com a violência da escola: uma violência institucional, simbólica, que os próprios jovens suportam através da maneira como a instituição e seus agentes os tratam (modos de composição das classes, de atribuição de notas, de orientação, palavras desdenhosas dos adultos, atos considerados pelos alunos como injustos ou racistas...). (CHARLOT, 2002, p. 434-435).

No segundo caso, a violência é direcionada à escola e a tudo que a representa: rituais, espaços físicos, materiais, professores e outros funcionários, indicando desacordos com as regras e os saberes por ela instituídos e, em última instância, com o projeto educacional, cultural e social que ela propõe. Como possibilidade de emancipação, a instituição escolar carrega dentro de si uma contradição inerente ao seu processo histórico de legitimação, especificamente com a difusão das escolas de massas do século XIX ao XX, que se propunha a trazer "as luzes", mas de forma comedida, de modo a não alterar o estado das coisas. Ao mesmo tempo em que apregoa a liberdade de pensar um mundo diferente e sem violência, comete-a quando impõe na sua ação pedagógica o arbitrário cultural, denominado assim já que esta ação não está assentada em uma realidade dada como natural, mas, sim, constitui a seleção de significações que define de forma objetiva a cultura de um grupo e/ou de uma classe, sustendo-a e perpetuando-a. A arbitrariedade relaciona-se à ideia de que a estrutura e as funções "dessa cultura não podem ser deduzidas de nenhum princípio universal, físico, biológico ou espiritual” (BOURDIEU, 2013, p. 29). Isto quer dizer que, ao selecionar saberes, posturas e comportamentos distintivos de uma determinada camada da população em seus programas, festas e rituais, a escola violenta deliberadamente a outra dessas camadas da população, desconsiderando, enfim, a capacidade 
fundamental do ser humano de elaborar de maneira criativa seus diferentes modos de pensar e atuar na realidade que o cerca.

A cultura escolar, concebida como um conjunto de normas forjadas externamente pelos legisladores, relacionadas aos conhecimentos a serem ensinados em currículos previamente aprovados e sugeridos às escolas e aos comportamentos a serem adquiridos pelos estudantes no processo de escolarização, bem como de práticas coordenadas às finalidades educativas (JULIA, 2001), é perpassada em todo o seu processo pelo que Pierre Bourdieu (2013) denominou violência simbólica, que se perpetua no seu cerne, na imposição legítima (porque aceita formal e informalmente) e dissimulada, com a interiorização da cultura dominante no âmbito escolar. Ou seja, a seleção de conhecimentos considerados legítimos para figurar nos programas das diferentes séries escolares funda-se na seleção arbitrária de um capital cultural $^{3}$ e de um habitus $^{4}$ que por vezes pode não ser o da população atendida pela escola.

A percepção das desigualdades escolares, transformadas a posteriori no fracasso escolar e até mesmo na violência escolar, se dá na valorização de qualidades e características que estão desigualmente distribuídas entre as classes sociais. O sucesso no processo de escolarização pressupõe certa naturalidade no trato com a cultura e o saber, que apenas aqueles que foram desde pequenos socializados na cultura legítima (considerada a cultura dominante) possuem (BOURDIEU, 2013). Desse modo, ao apregoar a escola pública e universal, dissimula-se em seu projeto recente a perpetuação da desigualdade social, por mecanismos bastante sofisticados e por vezes negligenciados, como tão bem discorreu Maria Helena de Souza Patto em A produção do fracasso escolar: histórias de submissão e rebeldia (2015), quando percebe que até mesmo o tom da voz ou a disponibilidade do(a) professor(a) para atender o estudante têm efeitos no seu processo de aprendizagem e acabam por afastar ou mesmo excluir os membros das camadas sociais mais desfavorecidos economicamente dos bancos escolares.

Se os alunos são os principais autores, mas não os exclusivos, das violências escolares, como percebemos a partir da análise do conceito de violência simbólica, são eles também as principais vítimas dessa violência. Entretanto a semelhança do ponto de vista estatístico entre os estudantes que sofrem e aqueles que realizam a violência escolar torna difícil a elucidação do conceito, segundo Charlot (2002). Trata-se de jovens considerados vulneráveis socialmente, alunos com dificuldades familiares, sociais e escolares, desempregados. Neste caso, uma análise mais acurada do fenômeno no contexto escolar necessitaria ultrapassar a presença da violência como sintoma e estudar a tensão 
engendrada pelas relações sociais e pelas práticas pedagógicas cotidianas da escola (CHARLOT, 2002): “[...] a educação tem sentido unicamente como educação dirigida a uma autorreflexão crítica" (ADORNO, 2000, p. 121).

Torna-se necessário superar as tendências regressivas contidas em todas as formas de violência, muito embora seja esta uma tendência social de nossos tempos de regressão psíquica. É urgente que superemos uma educação ainda calcada em normas e disciplinas, baseada na força e na dor: "[...] quem é severo consigo mesmo adquire o direito de ser severo também com os outros" (ADORNO, 2000, p. 128). Para que produzamos consciências não coisificadas, que sejam capazes de superar o atual estágio civilizatório sem cair em mais barbárie, precisamos informar e conscientizar as pessoas "acerca do jogo de forças localizado por trás da superfície das formas políticas”. Desvelar as regras do jogo, ensiná-las no cotidiano escolar, transformando os espaços educativos em locais de reflexão sobre os próprios processos de aprendizagem, geração e desenvolvimento de autonomia e emancipação poderia ser uma alternativa, mas não a única, para que ao menos o conceito de violência, tão presente nesses contextos, pudesse ser problematizado e encaminhado de forma mais criativa. Ou seja, não há regra geral, mas a possibilidade de, conhecendo a maquinaria escolar, fazê-la funcionar para propósitos emancipatórios. Quando se conhece as regras do jogo, há melhores condições de se defender e de saber atuar/agir de maneira mais arguta e estratégica no âmbito das relações escolares.

\section{Considerações finais}

As notícias deste mundo prenhe e de seu provável rebento chegam-nos de muitas partes do planeta; seja nas manifestações contrárias a governos antidemocráticos, totalitários e tirânicos; seja nas manifestações contra as guerras, que ainda teimam em acontecer em alguns pontos do nosso mundo; seja na luta contra os meios de comunicação de massa a serviço da classe dominante, que escravizam e encarceram os sujeitos em seus lares, cada vez mais privatizados e parecidos com pequenas penitenciárias, por formas democráticas de comunicação e informação; seja em manifestações por mais direitos, venham elas de grupos marginalizados e vulnerabilizados historicamente (negros, mulheres, crianças, idosos, índios, trabalhadores explorados, desempregados ou subempregados, gays e de orientação sexual diferente da "dominante") ou de outras partes também vulnerabilizadas (prisões, manicômios e instituições asilares em geral), de profissionais e formadores de opinião que clamam por 
justiça, a solidariedade, a justiça e a paz entre os povos são máximas a se atingir. Seja ainda naquelas escolas e naqueles estudantes que, em que pese as perspectivas completamente desfavoráveis proporcionadas pelas políticas públicas educacionais bastante empobrecidas, são portadores de mensagens de superação, resistência, luta e alegria ${ }^{5}$.

Se a escola é em grande parte, mas não totalmente, impotente quanto à violência em si mesma, ela dispõe ainda de estratégias de ação em face da violência à escola e da escola (CHARLOT, 2002, p. 435). Um primeiro e necessário movimento é desvendar o arsenal conceitual relacionado ao conceito e que se mistura a ele. O conceito de violência não deve ser confundido, por exemplo, com os de agressividade e conflito, considerando que a agressividade é uma disposição biopsíquica reacional à frustração, que, em determinados âmbitos, quando devidamente sublimada, como nas artes e nos esportes, pode mover o sujeito e realizar mudanças importantes na sociedade, cabendo à escola saber quais formas de agressividade e de conflito são legítimas ou aceitáveis para então as gerir. Há ainda que se considerar, para o tratamento da questão da violência, que os estudantes autores e os estudantes vítimas de violência se assemelham do ponto de vista estatístico: são jovens fragilizados, com dificuldades familiares, sociais e escolares (CHARLOT, 2002), condições que não obrigatoriamente levam à violência escolar, mas podem funcionar como disparadores para a criação de outros laços relacionais com a instituição escolar considerados mais férteis, como analisou Bernard Lahire em seu livro Sucesso escolar nos meios populares: as razões do improvável (2008), ao trazer histórias de vidas de estudantes que, apesar das condições consideradas adversas, tiveram percursos escolares exitosos, criando formas de elaborar o conceito de violência por meio da reflexão sobre como vivenciavam esse fenômeno em suas casas, na escola e em outros locais de socialização.

À transgressão e à incivilidade, que também não podem ser confundidas com o fenômeno da violência, a primeira entendida como o comportamento contrário aos regulamentos das instituições, no caso da escola, ao absenteísmo, a não realização dos trabalhos escolares e à falta de respeito; e o segundo, como o ataque às regras de boa convivência, propõe-se uma forma diferenciada de tratamento do saber escolar, de mobilização em relação à escola e ao saber, que supere seu tratamento utilitarista e os apresentem como instrumentos de construção/elaboração/emancipação do pensamento (CHARLOT, 1996, 2002). Ao lado dos aspectos "sagrados" consolidados pelo estado burguês (o dinheiro, o trabalho e o Estado), outros "sagrados" precisam se constituir. Se o Estado detém o monopólio da violência legítima, conforme esclarece Max Weber, legítimo também deve ser o direito de manifestação, já que 
"poucas vezes o Estado prova ser capaz de indenizá-lo (o cidadão) pelos sacrifícios que exige" (FREUD apud ENRIQUEZ, 1991, p. 142).

Acreditamos, como os frankfurtianos críticos e tantos outros, antes e depois deles, que a vida é possível de ser vivida e que a vida possível de ser vivida pode ser melhor do que é atualmente. Que aquilo que resta de Auschwitz e de tantos outros locais de extermínio da vida humana (física ou psíquica), como o Carandiru, o Vietnã, a Candelária, Vigário Geral, a Palestina, Altamira, Iraque, Líbano e Afeganistão, entre outros, sejam apenas recordações de um tempo superado:

O justo, nesse sentido, é, portanto, o proporcional e o injusto é aquilo que transgride a proporção. O injusto pode, assim, incorrer no excesso ou na deficiência (no "demasiado muito" ou no "demasiado pouco"), o que é realmente o que percebemos na prática, pois quando a injustiça é feita, aquele que a faz (o agente) detém o excessivo do bem em pauta e a vítima da injustiça detém o deficiente ou insuficiente desse bem, embora seja vice versa no caso de um mal, porque um mal menor comparado a um maior é tido como um bem, uma vez que o menor de dois males é mais desejável do que o maior; entretanto, o que é (efetivamente) desejável é bom e quanto mais desejável for, maior bem será. (ARISTÓTELES, 2002, p. 142-143).

É necessário retomar o "agir político" presente na histórica clássica; se é impossível nos desvencilhar de Thânatos, é possível que a luta interna contra Eros seja mais igual e mais homogênea. O “esvaziamento da esfera pública” (ARENDT, 2005), este “declínio do homem público” (SENNET, 1998), não nos torna melhores; nossas casas seguras em condomínios fechados, trancados, isolados e vigiados contra o "estrangeiro" não nos protegem da violência; na melhor das hipóteses, dissimulamna, colocam-na em outro local que não em nós mesmos, nem em nossas casas ou em nosso povo "ordeiro e submisso": "no fundo somos todos turistas e vagabundos" (BAUMANN, 1998a) circulando por espaços incertos, cada vez mais esquadrinhados. A globalização nos homogeniza a todos, massifica-nos, nos compele a uma eterna repetição e, por fim, conduz-nos à destruição psíquica (possivelmente também a física!). Se a totalidade não pode constituir-se sem injustiça, conforme nos apontou Levinas (1994 apud MATTEÍ, 2002, p. 340), é necessário repensar (e reunir) o junto e o separado, o local e o global, natureza e cultura, razão e emoção: nessa história, "se alguém vencer, é o fim para ambos” (WHEELER, 1968 apud ARENDT, 2010a, p.17).

\section{Notas}

${ }^{1}$ Reportagem recente divulgada em diferentes meios de comunicação impressa e televisiva deu-nos uma ideia mais aproximada dessa disparidade alarmante: segundo a Organização não Governamental inglesa Oxfam, 62 pessoas espalhadas pelo planeta detinham a metade da riqueza produzida até aquele momento. Na lista dos multimilionários estariam dois brasileiros. Disponível em: <http://www.bbc.com/portuguese/noticias/2016/01/160121_62_mais_ ricos_forbes_rp>. Acesso em: 13 abr. 2017. 
${ }^{2}$ Entrevista gravada com Eduardo Galeano. Disponível em: <http://quemtemmedodademocracia.com/2011/06/09/ eduardo-galeano-esse-mundo-de-merda-esta-gravido-de-outro-video-recente/>. Acesso em: 13 abr. 2017.

${ }^{3}$ De acordo com o sociólogo, o capital cultural pode existir sob três formas: no estado incorporado, no estado objetivado e no estado institucionalizado; dos três destacamos o estado incorporado, apresentado nas diferentes formas de disposições duráveis nos indivíduos e tendo como principais elementos constitutivos os gostos, o domínio maior ou menor da língua culta e de informações sobre o mundo escolar.

${ }^{4} \mathrm{O}$ conceito de habitus é definido por Bourdieu $(1986,2010)$ como um conjunto de esquemas de percepção, pensamento e ação capaz de orientar ou coagir práticas e representações. Para a elaboração do termo, retoma de Aristóteles a noção de hexis, que foi convertida pela escolástica em habitus, cuja definição desejou pôr em evidência as capacidades criadoras, inventivas, ativas do habitus e do agente; o habitus indica a disposição incorporada, "quase postural", de um agente em ação (BOURDIEU, 2010, p. 61), além disso, a noção serviria para descrever o funcionamento sistemático do corpo socializado.

${ }^{5}$ Nos últimos meses, o estado de São Paulo e o estado do Paraná foram palco de verdadeiras batalhas entre estudantes, pais e professores de um lado, e o poder público, representado pelos políticos que administram esses estados (governadores e seus secretários) e suas forças repressivas militares, de outro, com expressiva vitória simbólica dos primeiros, que ocuparam os espaços escolares e ali permaneceram por inúmeras semanas acampados, no caso de São Paulo, e com a grande repercussão internacional da truculência estatal contra a organização popular da categoria, no caso do Paraná, mostrando o quanto está viva a resistência estudantil e de seus pais e dos professores às políticas de desmonte da escola pública que vem se sucedendo no País. Disponível em: $<$ http://revistaeducacao.com.br/textos/0/entenda-a-evolucao-das-ocupacoes-de-escolas-em-sao-paulo-366953-

1.asp>.Acesso em: 13 abr. 2017 (São Paulo). Disponível em: <https://www.brasildefato.com.br/node/32168/>. Acesso em: 13 abr. 2017 (Paraná). 


\section{Referências}

ADORNO, T. Educação e emancipação. 2. ed. Tradução: W. L. Maar. São Paulo: Paz e Terra, 2000.

ARENDT, H. A condição humana. 10. ed. Tradução: R. Raposo. Posfácio: C. Lafer. Rio de Janeiro: Forense Universitária, 10 ed., 2005.

ARENDT, H. Eichmann em Jerusalém. Um relato sobre a banalidade do mal. Tradução: J. R. Siqueira. São Paulo: Companhia das Letras, 2010.

ARENDT, H. Sobre a violência. 2.ed. Tradução: A. M. Duarte. Rio de Janeiro: Civilização Brasileira, 2010a.

ARISTÓTELES. Ética a Nicômaco. Tradução: E. Bini. Bauru, SP: Edipro, 2002.

BAUMANN, Z. O mal-estar da pós-modernidade. Tradução: M. Gama e C. Martinelli Gama. Rio de Janeiro: Zahar, 1998a.

BAUMANN, Z. Modernidade e Holocausto. Tradução: M. Penchel. Rio de Janeiro, Zahar, 1998b.

BOURDIEU, P. A reprodução: elementos para uma teoria do sistema de ensino. Lisboa: Vega, 1978.

BOURDIEU, P. Coisas ditas. Tradução: C. Silveira e D. Pegorin. São Paulo: Brasiliense, 1990.

CAMUS, A. L'exil d'Hélène. Cahiers du Sud. In: . L’été. Essais. Paris: Galimard, 1965. Obra original publicada em 1948.

CAMUS, A. El verano. Tradução: A. L. Bixio. Barcelona: Edhasa, 1979. Obra original publicada em 1954.

CHARLOT, B. Relação com o saber e com a escola entre estudantes de periferia. Cadernos de Pesquisa, São Paulo, n. 97, p. 47-63, 1996.

CHARLOT, B. A violência na escola: como os sociólogos franceses abordam essa questão. Sociologias, Porto Alegre, v. 4, n. 8, p. 432-443, jul./dez. 2002. Disponível em: <http://www.scielo.br/pdf/soc/n8/n8a16>. Acesso em: 13 abr. 2017.

DAMERGIAN, S. O inconsciente na interação humana. Psicologia USP. São Paulo, v. 2, n. 1/2, p. 65-76, 1991. Disponível em: <http://pepsic.bvsalud.org/scielo.php?script=sci_arttext\&pid=S1678-51771991000100006>. Acesso em: 13 abr. 2017.

ENRIQUEZ, E. Da Horda ao Estado. Psicanálise do vínculo social. 2. ed. Tradução: T. C. Carreteiro e J. Nasciutti. Rio de Janeiro: Jorge Zahar, 1991.

FORRESTER, V. O Horror econômico. Tradução: A. Lorencini. São Paulo: Universidade Estadual Paulista, 1997.

FREUD, S. Totem e Tabu. São Paulo: Imago, 1976. Edição Standard Brasileira das Obras Completas de Sigmund Freud, v. XIII. Obra original publicada em 1913.

FREUD, S. Reflexões para os tempos de guerra e morte. São Paulo: Imago, 1976. Edição Standard Brasileira das Obras Completas de Sigmund Freud, v. XIV. Obra original publicada em 1932. 
HAINE, H. Os deuses no exílio. 1. reimpr. Tradução e organização: M. Suzuki e M. Kawano. São Paulo: Iluminuras, 2011. Coleção Biblioteca Pólen.

HELler, A. Para mudar a vida. Felicidade, liberdade e democracia. Entrevista a Ferdinando Adornato. Tradução: C. N. Coutinho. São Paulo: Brasiliense, 1982.

JASPERS, K. Razão e Anti-razão em nosso tempo. Tradução: A. V. Pinto. Rio de Janeiro: Instituto Superior de Estudos Brasileiros, 1958. Coleção Textos de Filosofia Contemporânea.

KLEIN, M.; HEIMANN, P.; MONEY-KYRLE. R. E. (Orgs.). Temas de Psicanálise Aplicada. Tradução: A. Cabral. Rio de Janeiro: Zahar, 1969.

LAHIRE, B. Sucesso escolar nos meios populares: as razões do improvável. Tradução: R. A. Vasques e S. Goldfeder. São Paulo: Ática, 2008.

LE BON, G. Psicologia das Multidões. Tradução: M. S. Cunha, Trad. Posfácio: M. C. Consolim. São Paulo: Martins Fontes, 2008. Obra original publicada em 1895.

LEITE, D. M. Psicologia Diferencial e estudos em educação. São Paulo: UNESP, 2008.

MARCUSE, H. Eros e civilização. Uma introdução filosófica ao pensamento de Freud. 5.ed. Tradução: A. Cabral. Rio de Janeiro: Zahar, 1972.

MARCUSE, H. A ideologia da sociedade industrial. O homem unidimensional. 4.ed. Tradução: G.Rebuá. Rio de Janeiro: Zahar, 1973.

MATTEÍ, J.-F. A barbárie interior: ensaio sobre o i-mundo moderno. Tradução: I. M. Loureiro. São Paulo: UNESP, 2002.

NAPOLEONI, L. Economia bandida. Tradução: P. J. Júnior. São Paulo: Difel, 2010.

PATTO, M. H. S. A Produção do Fracasso Escolar. Histórias de submissão e rebeldia. 4.ed. rev. e ampl. São Paulo: Intermeios, 2015.

SENNET, R. O declínio do homem público. As tiranias da intimidade. São Paulo: Companhia das Letras, 1998.

SERRES, M. O incandescente. Tradução: E. A. Carvalho e M. P. Bosco. Rio de Janeiro: Bertrand Brasil, 2005.

TASSARA, E. T. O.; DAMERGIAN, S. Para um novo humanismo: contribuições da Psicologia Social. Estudos Avançados, $\quad$ v. $10, \quad$ n. $28, \quad$ p. 291-316, $1996 . \quad$ Disponível em: <http://www.scielo.br/scielo.php?script=sci_arttext\&pid=S0103-40141996000300013>. Acesso em: 13 abr. 2017.

TOURAINE, A. Riscos do pensamento único. Folha de S. Paulo, São Paulo, 18 fev. 1996. Caderno Mais!, p. 57. Disponível em: <http://www1.folha.uol.com.br/fsp/1996/2/18/mais!/7.html>. Acesso em: 13 abr. 2017.

VARELA, J.; ALVAREZ-URIA, F. A Maquinaria Escolar. Teoria e educação, n. 6, p. 69-97, 1992.

WALLERSTEIN, I. El derrumbe del liberalismo. Secuencia, n. 28, p. 137-154, jan./abr., 1994. Disponível em: <http://secuencia.mora.edu.mx/index.php/Secuencia/article/view/455>. Acesso em: 13 abr. 2017. 
The multidimensionality of the violence concept:

elements for the debate

\begin{abstract}
The treatment multiplicity of current emergent social issues is infinite; diverse possibilities of theoretical analysis are possible for different issues concerning distinct scholars. Regarding these possibilities, this essay aims to discuss the violence concept based on scholars from psychology, psychoanalysis, sociology and also the education area. Furthermore, this work intends to show the violence phenomenon towards its complex and multifaceted perspective, pointing the educational process towards its humanization commitment, as possibility of reason emancipation and overcoming of human actions, known as violent in this world, which is too fragmented already, whose social relationships are too reified.
\end{abstract}

Key words: Violence. Violence in school. Reflection. Civilization and education.

Arlindo da Silva Lourenco

E-mail: arlindolourenco@uol.com.br

Renata Marcilio Candido

E-mail: remarcilio@gmail.com
La multidimensionalidad del concepto de la violencia: elementos para el debate

\section{Resumen}

La multiplicidad de tratamiento de las nuevas cuestiones sociales de hoy en día no tiene fin; varias posibilidades de análisis y de referencias teóricas son posibles para los diversos temas procedentes de diferentes autores. Teniendo em cuenta estas posibilidades, se pretende en este ensayo a cuestionar el concepto de la violencia y, para esto, utilizar algunos teóricos de la psicologia, el psicoanálisis, la sociologia y la educación. Mucho más allá de proponer alternativas de superación de el fenômeno de la violencia, evidencia de esto en su perspectiva compleja y polifacética, que indica el proceso educativo em su compromiso de humanización como una posibilidad para la emancipación de la razón y de la superación de las acciones humanas violentas en el mundo ya tan fragmentado, cuyas relaciones sociales son por lo cosificado.

Palabras clave: Violencia. Violencia en la escuela; reflexión. Civilización y educación.

Enviado em: 03/08/2016

Versão Final Enviada em: 24/04/2017

Aprovado em: 01/05/2017 